\title{
PASO 3: HACIA UNA EDUCACIÓN PRENATAL EN LACTANCIA MATERNA
}

\section{STEP 3: DO A PRENATAL EDUCATION IN BREASTFEEDING}

\author{
Margarita Eli Oscátegui Peña ${ }^{1 a}$
}

Estimado señor editor:

Luego de haber leído con interés el artículo "Factores asociados al nivel de conocimiento sobre lactancia materna exclusiva en madres primíparas atendidas por Teleconsulta - Instituto Nacional Materno Perinatal en el año 2020" por Vizquerra-Guevara $\mathrm{P}$, et al. publicado en el Volumen 10 número 1 de la Revista Peruana de Investigación Materno Perinatal, el cual considero un estudio de suma relevancia en el campo de la Obstetricia sobre todo en el campo de la Educación Materna; y teniendo en cuenta que en el año 2019, según ENDES el 65,6\% de niñas y niños menores de seis meses tuvieron lactancia materna ${ }^{1}$; quisiera acotar algunos aspectos que deberían considerarse para posteriores estudios.

Según la OMS y la UNICEF los diez pasos hacia una feliz lactancia natural (revisión 2018), se ha de cumplir con el paso 3 de información prenatal- Explicar a las mujeres embarazadas y a sus familias la importancia de la lactancia materna y su práctica ${ }^{2}$. Actualmente en las sesiones de psicoprofilaxis obstétrica, R.M. N ${ }^{\circ} 361-2011$ MINSA en la sesión $V$ brinda actividades educativas de Lactancia Materna, dicha guía es de aplicación en todos los establecimientos del Ministerio de Salud a nivel nacional ${ }^{3}$. Por otra parte, la RM N609-2014/MINSA establece la certificación de establecimientos amigos de la madre, la niña y el niño considerando que uno de los criterios de evaluación para la certificación es el paso 3 con los estándares siguientes:

- Se dispone de material informativo en lactancia materna en los ambientes de atención prenatal.

- Historias clínicas se encuentran registros de la consejería en lactancia materna durante la atención prenatal.

- Gestantes entrevistadas describen los riesgos de dar suplementos alimenticios en los primeros seis meses: describen la importancia del contacto precoz piel a piel y la importancia del inicio de la lactancia dentro de la primera hora de nacido.

- Gestantes entrevistadas conocen la importancia de la lactancia y refieren que el personal las ayuda a incrementar su propia confianza y seguridad.

- Personal entrevistado que atiende a las mujeres embarazadas demuestra que toca los temas claves en la consejería verbal durante la Atención prenatal ${ }^{4}$.

Asimismo; la RM No 353-2016/MINSA en el paso 3 establece que si el establecimiento de salud tiene al menos un servicio de atención prenatal debe ofrece la consejería de lactancia materna a las gestantes y a su familia acerca de la importancia de la lactancia, de los riesgos de no amamantar, de proporcionar sucedáneos, biberones, chupones, suplementos alimenticios y materiales para la alimentación artificial, la importancia de dar de lactar durante la primera hora de vida de su recién nacido, del contacto piel a piel, el pinzamiento oportuno del cordón umbilical, alojamiento conjunto y la lactancia materna a libre demanda ${ }^{5}$.

Es importante considerar las recomendaciones del MINSA sobre criterios, parámetros, indicadores que nos ayudan a medir el nivel de conocimiento sobre lactancia materna y la apertura de un consultorio de consejería en lactancia materna para las gestantes. La aplicación de toda la información indicada nos servirá como evidencias del trabajo que realiza la institución y el logro alcanzado.

\footnotetext{
1 Universidad Privada del Norte UPN, Facultad de Ciencias de la Salud

a Magister en Educación con mención en el nivel superior. Docente de la Escuela Profesional de Obstetricia de la UPN. Obstetriz Asistencial del Hospital de Vitarte

D Código ORCID: https://orcid.org/0000-0003-3671-7698, Margarita Eli Oscátegui Peña

Citar como: Oscátegui Peña ME. Paso 3: hacía una educación prenatal en lactancia materna. Rev Peru Investig Matern Perinat. 2021; 10(3): 11-12 DOI https://doi.org/10.33421/inmp.2021235
} 
Contribuciones de autoría: la autora ha participado en la concepción y aprobación de la versión final del manuscrito.

Declaración de conflictos de intereses: La autora declara no tener ningún conflicto de interés.

Financiamiento: Autofinanciado

\section{REFERENCIAS BIBLIOGRÁFICAS}

1. Instituto Nacional de Estadística e Informática. Encuesta Demográfica y de Salud Familiar (ENDES) 2019. https:// www.inei.gob.pe/media/MenuRecursivo/publicaciones_digitales/Est/Endes2019/

2. Organización Mundial de la Salud y el Fondo de las Naciones Unidas para la Infancia. Guía para la aplicación: proteger, promover y apoyar la lactancia materna en los establecimientos que prestan servicios de maternidad y neonatología - Revisión de la Iniciativa Hospitales Amigos del Niño 2018. ISBN 978-92-4-351380-5.

3. https://apps.who.int/iris/bitstream/handle/10665/326162/97 89243513805-spa. pdf?sequence=1\&isAllowed=y

4. Ministerio de Salud. Guía Técnica para la Psicoprofilaxis Obstétrica y Estimulación Prenatal. R.M. N 361-2011 MINSA. file:///E:/ARTICULO\%20DE\%2OINVESTIGACION\%20 UNFV/GUIA\%20TECNICA\%20DE\%20PSICO.pdf

5. Ministerio de Salud. Directiva Administrativa para la Certificación de Establecimientos de Salud Amigos de la Madre, la Niña y el Niño. Directiva Administrativa $N^{\circ} 2 \mathrm{D}$ -MINSA/DGSP-V.01. . RM No609-2014/MINSA. https:// cdn.www.gob.pe/uploads/document/file/201796/198560_ RM609_2014_MINSA.pdf20180926-32492-tbokmf.pdf

6. Ministerio de Salud. Directiva Administrativa para la Certificación De Establecimientos de Salud Amigos de la Madre, la Niña y el Niño. Directiva Administrativa No. 201- MINSA/ DGSP. V.01. RM No 353-2016/MINSA. https://cdn.www.gob. pe/uploads/document/file/193595/192319_RM_353-2019MINSA_.pdf20180904-20266-zv0tqm.pdf

\section{Correspondencia:}

Margarita Eli Oscátegui Peña

Dirección: Los Flamengos \# 546 Santa Anita

Correo: oscateguipeamargarita@gmail.com

Teléfono: 996811243 